\title{
REFORMA DA EDUCAÇÃO PROFISSIONAL: CONTRADIÇÕES NA DISPUTA POR HEGEMONIA NO REGIME DE ACUMULAÇÃO FLEXÍVEL
}

\author{
PROFESSIONAL EDUCATION REFORM: CONTRADICTIONS IN THE FIGHT FOR HEGEMONY IN \\ THE FLEXIBLE ACCUMULATION SYSTEM
}

Marise Nogueira Ramos ${ }^{1}$

Resumo Este texto comenta e debate algumas idéias apresentadas por Kuenzer em artigo deste número, sob a perspectiva das disputas hegemônicas de grupos que ocupam o aparelho de Estado na sua relação com a sociedade civil. Retomamos a análise de forças políticas que influenciaram a reforma feita pelo decreto $\mathrm{n}^{\circ} 2.208 / 97$, discutindo a opção do primeiro governo Lula em reorientar a política pública de educação profissional na direção de compromissos assumidos com os setores progressistas. Não obstante, este processo trouxe contradições no conteúdo e na forma da 'nova' política. A educação profissional no Brasil, mesmo em tempos de complexificação da base técnico-científica da produção, ocupa-se da formação para o trabalho simples, enquanto utiliza dispositivos de controle simbólico, associados à idéia de cidadania e de intervenção social. Em relação ao trabalho complexo, os projetos em discussão não trazem à cena a necessária publicização da produção de ciência e tecnologia, a ser orientada pela vinculação orgânica entre educação omnilateral e politécnica dos trabalhadores, política pública de ciência e tecnologia e projeto de nação soberana. Concluímos que essa concepção ainda não é hegemônica na sociedade civil nem prioridade no aparelho governamental. A análise desses fenômenos e suas contradições nos fazem aprender com a história.

Palavras-chave educação profissional; políticas educacionais; reforma educacional.
Abstract This article comments on and debates a few ideas presented by Kuenzer in an article published in this edition regarding the perspective of the hegemonic contentions among the groups that occupy the State in its relationship with the civil society. We have resumed the analysis of the public forces that influenced the reform made by decree \# 2.208/97 by discussing the choice made by the first Lula administration to redirect the public professional education policy towards the commitments taken-on with progressive sectors. Nonetheless, this process brought contradictions to the 'new' policy's content and form. Brazil's professional education, even in an era in which the technical and scientific base of production has become more complex, seeks to qualify people for simple work while using symbolic control devices in association with the idea of citizenship and social intervention. So far as complex work is concerned, the projects under discussion do not bring the needed science and technology production publicization under the spotlight, one that should be guided by the organic bind between the workers' omnilateral and polytechnic education, public policy for science and technology, and the design of a sovereign nation. We conclude this conception is neither hegemonic in the civil society nor a governmental priority. By analyzing these phenomena and their contradictions, we can learn with history.

Keywords professional education; educational policies; educational reform. 


\section{Formação do trabalhador flexível: o objetivo da reforma pós-LDB}

O artigo que Kuenzer traz a debate nos instiga a aprofundar a compreensão sobre o caráter da educação profissional no regime de acumulação flexível, com base no qual o capital passa a requisitar do trabalhador determinadas características condensadas na genérica e polêmica noção de competências. A apropriação dessa noção pela política educacional brasileira, como uma referência para colocar em relação educação e dinâmica produtiva, foi consubstanciada na legislação que se seguiu à promulgação da (LDB), a fim de regulamentá-la.

Naquele momento (1996), para além de alguns poucos estudos acadêmi$\cos ^{2}$ e outros advindos de setores empresariais ${ }^{3}$, o significado da noção de competência era permeado pelo senso comum. A própria LDB se refere de uma forma um tanto quanto indefinida a este termo, por exemplo quando determina à União "estabelecer, em colaboração com os Estados, o Distrito Federal e os Municípios, competências e diretrizes para a educação infantil, o ensino fundamental e o ensino médio, que nortearão os currículos e seus conteúdos mínimos, de modo a assegurar formação básica comum" (lei nº 9.394/96, artigo 9º, inciso IV).

É o decreto $n^{\circ} 2.208 / 97$ e sua posterior regulamentação que darão uma certa conotação 'científica' à noção de competências, a ser utilizada como principal referência para a elaboração de currículos de cursos de educação profissional. Também as diretrizes do ensino médio e, mais tarde, as do ensino superior, foram formuladas nesses termos. Enquanto a tendência ao esgotamento dos padrões tayloristas-fordistas de qualificação do trabalhador ocupava o debate em países de capitalismo avançado, os países da América Latina recebiam orientações da Organização Internacional do Trabalho (OIT) para a organização de sistemas de competência profissional, conjugadas a diretrizes do Banco Interamericano de Desenvolvimento (BID) para a realização de reformas em seus sistemas de ensino.

Essas orientações, formuladas e divulgadas com o auxílio e apoio de autoridades e intelectuais brasileiros, tratavam de definir o ensino técnico de nível médio - sob a lógica fordista, considerado adequado à formação de profissionais para o exercício de funções intermediárias da produção, tais como execução técnica, manutenção, controle e supervisão - como dispendioso ao Estado e inócuo para a classe trabalhadora. Isto porque sua restrita oferta e rigidez curricular, associadas a uma boa qualidade, atraíam predominantemente os jovens da classe média que o faziam como 'trampolim' para a universidade, diminuindo, assim, as oportunidades de acesso a grupos menos favorecidos. Esses argumentos sustentaram a principal mudança ocorrida na educação brasileira ao longo de 25 anos (de 1971, ano da lei no 5.692, a 1997, ano do decreto $\mathrm{n}^{\circ}$ 2.208), qual seja, a desvinculação da formação técnica 
de nível médio da educação secundária, denominada pela nova LDB como ensino médio.

A adoção do modelo de competências pela educação profissional completou a reforma curricular. Neste introduz-se não somente o currículo baseado em competências como também a avaliação e a certificação por competências. Promover o convencimento de educadores quanto à pertinência desse modelo, bem como orientar a implementação da reforma foi o principal trabalho do Ministério da Educação, com seus consultores e articuladores nas esferas estaduais e municipais. Não faltou suporte financeiro a essas ações, especialmente a partir de empréstimos do BID para o desenvolvimento de programas de 'expansão e melhoria' da educação profissional (Programa de Expansão da Educação Profissional - Proep) e do ensino médio (Programa de Melhoria e Expansão do Ensino Médio - Promed), ambos geridos pelo Ministério da Educação, além do Projeto de Profissionalização dos Trabalhadores da Área de Enfermagem (Profae), do Ministério da Saúde. Sem a sustentabilidade do BID, mas com recursos do Fundo de Amparo ao Trabalhador (FAT), o Ministério do Trabalho e Emprego cuidou dos programas de formação para o trabalho simples no contexto de desemprego, tal como foi o Plano Nacional de Qualificação do Trabalhador (Planfor).

Além de segmentar a formação dos trabalhadores em níveis - grosso modo correspondentes aos respectivos patamares de escolaridade (segundo o decreto $\mathrm{n}^{\circ}$ 2.208/97, o nível básico da educação profissional, apesar de não predeteminar a escolaridade exigida, atendia aos trabalhadores com ensino fundamental; e o nível técnico, aqueles cursantes ou concluintes do ensino médio) - introduziu-se o 'nível superior da educação profissional' chamado de tecnológico. A análise dessas medidas à luz da reestruturação capitalista nos permite identificá-las como meios de adequação da formação de trabalhadores ao regime de acumulação flexível. Listamos: a) diminuição dos custos do Estado com os cursos técnicos de nível médio; b) substituição desses pelos cursos superiores de tecnologia, com menor custo do que os cursos técnicos e os de graduação, dadas a sua natureza e a carga horária. Tais cursos, além de aliviar a pressão sobre o nível superior, por se tornar uma alternativa, assumiriam a função de formar técnicos adequados ao novo patamar científico-tecnológico da produção.

Ter-se-iam, assim, atingidos os objetivos de adequação à acumulação flexível: política de capacitação de massa, com finalidades compensatórias ao desemprego, por isto sustentada no argumento da empregabilidade; barateamento dos custos profissionalizantes; criação de caminhos alternativos às universidade e, finalmente, o não aniquilamento da necessária camada de técnicos adequados ao processo de reestruturação produtiva, já que os formandos dos cursos de tecnólogos teriam as seguintes características: competências gerais e abstratas desenvolvidas a partir de curso de nível superior e com- 
petências específicas adquiridas pela profissionalização. Esta combinação entre competências gerais e específicas seria a síntese da formação flexível. Conforme diz Kuenzer, no texto sob discussão, na flexibilidade da força de trabalho "importa menos a qualificação prévia do que a adaptabilidade, que inclui tanto as competências anteriormente desenvolvidas, cognitivas, práticas ou comportamentais, quanto a competência para aprender e para submeter-se ao novo, o que supõe subjetividades disciplinadas que lidem adequadamente com a dinamicidade, com a instabilidade, com a fluidez".

Assim se explica o fato de a formação técnica de nível médio integrada ao ensino médio não ter ocupado lugar na política educacional e nas opções dos sistemas de ensino, como também a tendência dos Cefets de ofertarem cada vez menos cursos técnicos, sejam eles integrados ou não. Na acumulação flexível, a força de trabalho simples poderia prescindir de uma formação técnica, já que as operações, realmente, se simplificam. Para a força de trabalho competências flexíveis genéricas são mais necessárias do que as específicas, para que a adaptação aos arranjos produtivos possa ser ágil. Tais competências podem ser desenvolvidas no ensino médio, que, aliás, tem por finalidade exatamente o desenvolvimento de competências cognitivas e comportamentais. No âmbito dos tecnólogos, por se posicionarem em ocupações de maior complexidade, a flexibilidade adviria também de um conhecimento específico, de base científico-tecnológica, porém, nos limites das finalidades aplicadas e práticas da ciência.

\section{A contra-reforma no governo Lula: contradições de uma política de (não)Estado}

Kuenzer inicia a análise das políticas e propostas de educação profissional em tempos neoliberais, não diferenciando as dos governos Fernando Henrique Cardoso e Luiz Inácio Lula da Silva, no que diz respeito às relações entre Estado e sociedade civil. Discutiremos aqui algumas contradições que nos ajudem a pensar sobre os alcances e limites das proposições e realizações do governo Lula sob este prisma.

Sabemos que um dos compromissos de campanha do candidato Lula para com a educação era a revogação do decreto $n^{\circ} 2.208 / 97$. Entretanto, esta medida não foi tomada de imediato, tanto em razão de inseguranças internas à equipe ministerial sobre 'o que colocar no lugar', quanto a influências de grupos que não tinham interesse em sua revogação, a exemplo dos diretores de Cefets, secretários estaduais de Educação e representantes do Sistema S4, sistema nacional de aprendizagem a cargo do comércio e da indústria. A opção por uma construção com a sociedade civil assim se explica, tendo se expressado nos seminários realizados em 2003, um sobre o ensino médio ${ }^{5}$ e outro sobre 
a educação profissional6. A participação aberta às instituições neste último proporcionou a articulação com os segmentos conservadores, tornando o processo e a forma de revogação do decreto muito mais difíceis do que, talvez, o teria sido por uma ação logo ao início do novo governo. Em termos de uma política efetiva, entretanto, a revogação do decreto não era suficiente, pois implicaria o redirecionamento dos recursos para fins públicos7.

A história de fato mostrou, como argumenta Kuenzer, que, ao invés da publicização radical das políticas de educação da classe trabalhadora, o que se viu foi uma crescente privatização. Representantes de setores públicos, por exemplo, se uniram a setores privados 8 para defender a manutenção do referido decreto, pelo eixo do pragmatismo e do corporativismo, ainda que, implicitamente, guardassem dimensões políticas e ideológicas. Dentre as razões manifestas para sua manutenção, predominavam a defesa da flexibilidade da oferta da educação profissional gerada por esta política, segundo eles mais adequada às finalidades das instituições e às demandas da sociedade. Tal flexibilidade, no entanto, potencializou a venda de serviços pelas instituições privadas e abriu caminho para a mesma prática pelas instituições públicas; prática essa reforçada pelos critérios adotados pelo Proep, que se dispôs a fazer investimento nessas instituições, desde que as demonstrassem capacidade crescente de auto-sustentabilidade.

Frente a essa realidade, Kuenzer indaga sobre a verdadeira intenção do decreto $\mathrm{n}^{\circ}$ 5.154/2004, que revogou o 2.208/97, “porque, embora 're-crie' os cursos médios integrados, o que não seria necessário por estarem eles contemplados no parágrafo $2^{\circ}$ do art. 36 da lei 9.294/96, incorpora todas as modalidades de educação profissional por ele propostas, com pequenas mudanças de denominação". Naquela época, a equipe da Secretaria de Educação Média e Tecnológica (Semtec/MEC) entendia que a simples revogação do decreto $\mathrm{n}^{0}$ 2.208/97 não garantiria a implementação da nova concepção de ensino médio e educação profissional e tecnológica. Não há divergência de princípios e de concepções entre esta e a posição da autora, mas sim de avaliação política sobre a forma de encaminhamento. Quanto à manutenção das modalidades previstas pelo decreto anterior, valem alguns comentários.

Primeiramente, consideramos importante reconhecer que, em relação aos chamados cursos de nível básico da educação profissional, procurou-se tanto rever sua nomenclatura num sentido mais adequado à finalidade de proporcionar aos trabalhadores jovens e adultos o direito à qualificação inicial e à educação continuada, quanto integrá-los a itinerários formativos que redundassem em formações estruturadas integradas às etapas da educação básica.

Quanto ao ensino técnico de nível médio, o objetivo principal era superar o impedimento de se integrar curricularmente o ensino médio e a formação técnica, desde que esta não substituísse a formação básica do educando, conforme prevê o parágrafo $2^{\circ}$ do artigo 36 da LDB. É preciso reconhecer que à le- 
galidade conferida a esta forma não correspondeu, necessariamente, o sentido ético-político que orientou a defesa da indissociabilidade entre formação geral e específica baseado na concepção de formação omnilateral. Não obstante, identificamos essa forma como a que corresponde às necessidades e aos direitos dos trabalhadores, pelo fato de admitir a realização de um único curso com duração de, pelo menos, quatro anos, possibilitando, ao final, conclusão da educação básica e da educação profissional. Já discutimos que a forma integrada do ensino médio à educação profissional não se confunde totalmente com o projeto de escola unitária e educação politécnica porque a conjuntura do real assim não o permite. Porém, por conter elementos de uma educação politécnica, vem a ser uma condição social e historicamente necessária para a sua construção, buscando-se, a partir do desenvolvimento do capitalismo e de sua crítica, superar a proposta burguesa de educação que potencialize a transformação estrutural da realidade. Assim,

“o ensino médio integrado é aquele possível e necessário em uma realidade conjunturalmente desfavorável - em que os filhos dos trabalhadores precisam obter uma profissão ainda no nível médio, não podendo adiar este projeto para o nível superior de ensino - mas que potencialize mudanças para, superando-se essa conjuntura, constituir-se em uma educação que contenha elementos de uma sociedade justa" (Ramos, Frigotto e Ciavatta, 2005)

Quanto à forma concomitante, em que a formação técnica ocorre paralelamente ao ensino médio, em currículos e em estabelecimentos de ensino distintos $^{9}$, identificamos como uma alternativa face aos limites dos sistemas de ensino de implantar universalmente a forma integrada. Mas uma formação coerente exigiria uma unidade político-pedagógica interinstitucional. Isto não é fácil, posto que, se numa mesma escola esta unidade é sempre um desafio, quanto mais não o seria quando implicam duas instituições. Por essa razão, consideramos que a concomitância só faz sentido quando as redes de ensino não têm condições de oferecer o ensino médio integrado, mas sempre como transição e não como opção definitiva.

Na forma subseqüente, por fim, a educação profissional se constitui como educação continuada, de modo que o jovem e o adulto que tenham concluído o ensino médio não profissionalizante possam ainda fazer a formação profissional. Ou, tendo já uma formação profissional, possam buscar atualizações ou outras profissões. Essa é uma lógica de educação continuada que deve constar também das obrigações dos sistemas de ensino. Porém, ela não se confunde com uma alternativa compensatória ao ensino superior. $\mathrm{O}$ acesso ao conhecimento é um direito em todos os níveis de ensino.

A forma integrada de oferta do ensino médio com a educação profissional obedece a algumas diretrizes ético-políticas, a saber: integração de conheci- 
mentos gerais e específicos; construção do conhecimento pela mediação do trabalho, da ciência e da cultura; utopia de superar a dominação dos trabalhadores e construir a emancipação - formação de dirigentes. Sob esses princípios, é importante compreender que o ensino médio é a etapa da educação básica em que a relação entre ciência e práticas produtivas se evidencia, e é a etapa biopsicológica e social de seus estudantes em que ocorrem o planejamento e a necessidade de inserção no mundo do trabalho, no mundo adulto. Disto decorre o compromisso com a necessidade dos jovens e adultos de terem a formação profissional mediada pelo conhecimento.

Restaria uma consideração, ainda, sobre a graduação tecnológica. A definição da graduação e da pós-graduação tecnológica como um dos níveis da educação profissional não foi debatida adequadamente e não se avaliou seu significado científico e político. Afinal, o que vem a ser a graduação profissional e a graduação acadêmica? Esta questão já existia desde a década de 1960, quando foram criados os cursos de Engenharia de Operação e de formação de tecnólogos, diferenciados dos cursos de vertente 'acadêmica' por seu conteúdo mais tecnológico do que científico. Quanto à pós-graduação, talvez o mestrado profissionalizante responda a essa pergunta.

O decreto $\mathrm{n}^{\circ}$ 2.208/97 recolocou essa modalidade com o 'nível tecnológico', o que alavancou uma expansão brutal de cursos superiores de tecnologia na esfera pública, mas de forma vertiginosa, na esfera privada10, além de institucionalizar a extensão da dualidade educacional para o nível superior. No debate sobre o decreto $\mathrm{n}^{0} 5.154 / 2004$, pouco se consideraram as implicações e contradições de se definir, no artigo $1^{\circ}$, inciso III, que a educação profissional seria desenvolvida por meio de cursos e programas de "educação profissional tecnológica de graduação e de pós-graduação". Além de não resolver o pro-blema da identidade e das finalidades socioeducacionais de instituições como os Cefets, por exemplo, esta prerrogativa pode dar respaldo à tendência de se consolidar a educação profissional como uma modalidade educacional própria, específica e paralela à educação regular, em todos os níveis da educação nacional.

Hoje, esta questão se insere no debate sobre a transformação dos Cefets em universidades tecnológicas e/ou em institutos federais de Educação, Ciência e Tecnologia11, projeto apoiado pelo MEC. Se, por um lado, não se pode elidir a contribuição histórica dos Cefets mais antigos 12 para a formação de profissionais de nível superior, precisa-se admitir que sua origem e desenvolvimento diferem das universidades, em razão de determinações históricas que comprometeram esse projeto mais com o capital do que com o trabalho, mais com o mercado do que com os trabalhadores.

Num plano de contradições, o movimento dessas instituições tentou inverter esse sentido, numa luta contra-hegermônica árdua, especialmente nos anos de 80 e 90 . Atualmente, porém, toma centralidade uma defesa muito mais 
coorporativa do que ético-política da formalização institucional dessas instituições como universidades ou equivalentes ${ }^{13}$. Neste projeto, se acirra uma concepção utilitarista de ciência e tecnologia, com todas as conseqüências decorrentes em termos da privatização do processo de produção e de apropriação do conhecimento científico-tecnológico; vincula-se a formação a demandas econômicas, em detrimento das necessidades dos trabalhadores e de um projeto de país soberano; negligencia-se a formação de jovens e adultos na perspectiva omnilateral e politécnica, rejeitando-se, em termos relativos, a oferta do ensino médio integrado, em nome da oferta de cursos superiores de tecnologia e de licenciaturas, numa perspectiva expansionista, regulada por interesses diversos e pouco comprometidos com a qualidade e a identidade ético-política que se veio tentando construir na luta social.

Obviamente, o debate sobre a política de ensino superior no Brasil implica pensar a universidade brasileira em suas raízes, contradições e perspectivas, à luz também de um projeto de nação ${ }^{14}$. Nesse sentido, consideramos que um tema central é a mediação estratégica dessas instituições, incluindo os Cefets, na ampliação do caráter público da ciência, da tecnologia e da produção social de bens para a satisfação das necessidades humanas. Enfrentar esse debate no âmbito das políticas de educação profissional exige superar a histórica subsunção do Estado à dinâmica do capital. Se as 'intenções' que guiaram a elaboração do decreto $\mathrm{n}^{\circ}$ 5.154/2004 a partir dos interesses da classe trabalhadora foram 'transformados' 15 em benefício do capital, talvez não tenhamos conquistado, no âmbito da sociedade civil, a hegemonia necessária para assumirmos a direção política da sociedade.

\section{Uma educação que recupere o conhecimento científico como mediação da formação omnilateral e politécnica}

Kuenzer bem analisa que as propostas de educação profissional que vêm sendo levadas a efeito evidenciam que, embora as mudanças ocorridas no mundo do trabalho passem a exigir ampliação da educação básica com qualidade, fundada no domínio técnico-intelectual enquanto relação entre conhecimentos e competências cognitivas complexas, o que se vem oferecendo aos que vivem do trabalho se resume à reprodução do conhecimento tácito. Essa constatação nos leva a estranhar que se requeira tão fortemente o vínculo entre escola e produção, num momento em que o aumento do nível de abstração das forças produtivas leva a uma simplificação na execução do trabalho, de um lado, e à dispensa de trabalhadores qualificados, de outro.

Em trabalho de nossa autoria (Ramos, 2001), nos colocamos uma questão correlacionada à constatação de Kuenzer, a saber: na tendência de os processos educativos visarem ao desenvolvimento de competências básicas e profissio- 
nais adequadas à flexibilidade do mercado de trabalho e da produção, teriam lugar os conhecimentos científicos ou a formação limitar-se-ia aos aspectos da personalidade?

Para Dubar (1998), os conhecimentos transmitidos e adquiridos no sistema educativo representaram um dos recursos dos egressos na sua negociação para a entrada no mercado de trabalho. A articulação entre sistema educativo e sistema produtivo dependia, em parte, da gestão desses conhecimentos. Se, num passado recente, dir-se-ia da inserção profissional ser o "momento em que o indivíduo vai procurar negociar os conhecimentos adquiridos para conseguir um emprego" (Dubar, 1998, p. 167), hoje seriam negociadas suas competências, principalmente em termos de sua personalidade flexível. É o tipo de articulação entre sistemas educativo e produtivo, então, que se modifica. Bernstein (1996) nos ajuda a compreender essa mudança quando analisa as relações entre campo da produção, campo do controle simbólico e educação.

No campo do controle simbólico estariam atualmente as novas profissões que regulam a mente, o corpo, as relações sociais, seus contextos especiais e suas projeções temporais, ao passo que os agentes do campo da produção regulam os recursos físicos. Ambos os campos controlam os meios, os contextos e as possibilidades de realização. Enquanto o campo da produção estar-se-ia simplificando, o campo do controle simbólico estaria ampliando suas funções normalizadoras em decorrência do enfraquecimento da disciplina do trabalho. Por isto o vínculo entre educação e produção permaneceria forte somente nos níveis superiores de educação - quando se formariam os trabalhadores informacionais ou autoprogramáveis, nos termos de Castells (1998). Mas o vínculo entre educação e controle simbólico estaria se fortalecendo e se generalizando em todos os níveis. Essa visão ratifica o papel da educação muito mais na conformação da personalidade e da consciência do que os conhecimentos técnico-científicos.

Explica-se, assim, conforme Kuenzer afirma, que os projetos de educação profissional contemplem "uma amálgama de qualificação social entendida como ação comunitária, aprendizagem de fragmentos do trabalho no espaço produtivo como conhecimento científico-tecnológico, domínio de algumas ferramentas da informática e das linguagens como capacidade de trabalho intelectual, discussão sobre algumas dimensões da cidadania como capacidade de intervenção social, levando a entender que o resultado deste conjunto configura-se como educação para a inclusão social".

"Ação comunitária", "domínio das linguagens", "capacidade de intervenção social" são competências importantes no campo do controle simbólico, pois desenvolvem no trabalhador um sentimento de responsabilidade para consigo e sua comunidade, ao ponto de que eles próprios devem buscar as soluções para o desemprego, para a miséria, para a exclusão. Muito além de uma flexibilidade necessária à produção, uma vez que a maior probabilidade é 
de que eles não estejam nela inseridos, este é um tipo de flexibilidade externa, qual seja, a necessária para buscar emprego, trabalhar em tempo parcial ou em condições precárias, atuar voluntariamente em projetos sociais etc. Para a produção, a aprendizagem de 'fragmentos do trabalho' é suficiente, pois o trabalho a ser realizado pelos sujeitos de programas de formação como os referidos pela autora é, tendencialmente, tão simples quanto o foi no início do fordismo.

Em um país em que a política de ciência e tecnologia não é tanto de geração de novos conhecimentos, e mais de adaptação ou inovação tecnológica, a tendência à simplificação do trabalho é cada vez maior, de modo que uma também simples formação técnica seja suficiente, conjugada com alguns dispositivos de 'controle simbólico'. Somado a isto, a crescente tecnologização da ciência aumenta o peso de seu valor instrumental em detrimento do seu valor intrínseco, contribuindo para o processo de mercantilização, promovido por um refinamento no conceito de aplicação. Em sentido inverso, a produção de novos conhecimentos exigiria uma autonomia relativa da ciência em relação à produção. Em razão disso, é uma ciência que precisa se desenvolver no espaço público, financiada pelo fundo público.

Um projeto de educação profissional contra-hegemônico, ou seja, comprometido com a soberania da nação e com os interesses de sua classe trabalhadora, procuraria unificar organicamente a formação de trabalhadores de nível médio e superior nos campos da ciência, tendo como base uma formação omnilateral e politécnica. Esta, no nível médio, se fundamentaria na integração entre trabalho, ciência, tecnologia e cultura, superando a 'rarefação' dos conhecimentos humanísticos e sociais, bem como a fragmentação entre formação geral e específica, ou humanista e científica, que caracterizou a história da educação brasileira. Esse ensino se apresentaria como uma síntese superadora do academicismo clássico e do profissionalismo estreito.

O ensino superior, por sua vez, corresponderia ao aprofundamento da formação científico-tecnológica nas diversas áreas do conhecimento, com o propósito de formar intelectuais para a produção e o desenvolvimento científico-tecnológico no Brasil, em coerência com os princípios que definem uma formação universalizante. Seria nessa perspectiva que poderíamos superar os limites da política de educação dos trabalhadores, revertendo seu projeto para os interesses da sociedade.

\section{Lutar por outra hegemonia na educação: desafio da sociedade civil}

Ao início do governo Lula, tentou-se publicizar interesses e conflitos sobre a política de ensino médio e educação profissional, com apoio na idéia de que o Estado se educa com a sociedade e, ao mesmo tempo, tem a prerrogativa de educá-la. Porém, as contradições, os compromissos iniciais e as políticas focais 
e compensatórias voltadas para os trabalhadores brasileiros demonstrariam um 'transformismo': a cooptação das principais lideranças da oposição pelo bloco no poder. Em que medida o projeto nacional democrático popular não se dissolveu pela inserção subordinada do Brasil na economia internacional globalizada e, dessa forma, se justificam as políticas de educação profissional adequada ao trabalho simples?

Não obstante toda a expectativa em contrário, a vitória das forças conservadoras tem, de fato, feito predominar a manutenção de princípios e práticas que orientaram as reformas no governo Fernando Henrique Cardoso. A insistência de alguns setores políticos e intelectuais em explicitar o fenômeno tenta, pelo menos, manter aceso o debate e abertos os espaços da contradição, que devem ser enfrentados mais na sociedade civil do que no aparelho de Estado, posto que neste interesses de grupos privados parecem ter-se cristalizado. A necessidade de se construir a hegemonia de uma outra concepção de mundo na sociedade civil, para que o bloco que ocupe o poder não o exerça pela dominação, é uma lição que, nos parece, a história nos desafia a aprender. Buscar, então, compreender as diferentes determinações que nos conduziram até onde estamos é um imperativo ético-político.

No plano educacional, insistimos na politecnia como uma utopia sempre em construção, como uma concepção que compreende o trabalhador como sujeito de realizações, de conhecimentos e de cultura, capaz de transformar a realidade dada em realidade para si. O avanço dessa construção pressupõe o rompimento não só com as antigas vertentes tecnicistas e condutivistas da educação, mas também com aquelas mais contemporâneas, sustentadas pela apologia ao novo, em que predomina o controle simbólico sobre os trabalhadores e a "inclusão excludente" de que nos fala Kuenzer. Resgatar preocupações que as tendências neoconservadoras nos quiseram fazer esquecer talvez seja um dos primeiros compromissos a ser assumido em busca de uma outra hegemonia.

\section{Notas}

1 Professora do Centro Federal de Educação Tecnológica de Química, em exercício de cooperação técnica como pesquisadora e coordenadora do Programa de Pós-Graduação em Educação Profissional em Saúde da Escola Politécnica de Saúde Joaquim Venâncio, da Fundação Oswaldo Cruz (EPSJV/Fiocruz), Rio de Janeiro, Brasil. Professora adjunta do Programa de Pós-Graduação em Políticas Públicas e Formação Humana (PPFH) da Faculdade de Educação da Universidade do Estado do Rio de Janeiro (Uerj). Doutora em Educação pela Universidade Federal Fluminense (UFF).<mnramos@oi.com.br> 
Correspondência: Universidade do Estado do Rio de Janeiro, Centro de Educação e Humanidades, Faculdade de Educação, Rua São Francisco Xavier, 524, bloco B, $12^{\circ}$ andar, sala 12.111, Maracanã, Rio de Janeiro, Brasil, CEP 20550-900.

2 Citamos, particularmente, a tese de doutorado de Deluiz (1995). Em 1997, uma obra organizada por Ropé e Tanguy foi lançada no Brasil e se constituiu numa referência acadêmica importante sobre o tema, especialmente por abordar o uso da noção de competências na escola e na empresa. Posteriormente, várias obras de Perrenoud ocuparam o mercado editorial, dentre as quais destacamos a de 1999. O MEC declarou tê-las utilizado como referência para as reformas curriculares.

3 O principal estudo é de Mertens (1996).

4 O Sistema S inclui: Serviço Nacional de Aprendizagem Industrial (Senai), Serviço Nacional de Aprendizagem Comercial (Senac), Serviço Social da Indústria (Sesi), Serviço Social do Comércio (Sesc), Serviço Social de Transporte (Sest), Serviço Nacional de Aprendizagem do Setor Transporte (Senat), Serviço Nacional de Aprendizagem Agrícola (Senar), Serviço Brasileiro de Apoio a Micro e Pequenas Empresas (Sebrae) e Serviço Nacional de Aprendizagem do Cooperativismo (Sescoop).

5 O seminário nacional Ensino Médio: construção política, realizado em Brasília nos dias 4 a 6 de junho de 2003, teve como eixo e balizamento da concepção de ensino médio o conhecimento, o trabalho e a cultura e foi precedido por um conjunto de oficinas preparatórias, cujo material produzido foi publicado pelo Ministério da Educação em livro organizado por Frigotto e Ciavatta (2004), sob a coordenação editorial desta autora. As sínteses dos debates ocorridos durante o seminário, por sua vez, foram também publicadas (Brasil, 2004b).

6 O seminário nacional Educação Profissional: concepções, experiências, problemas e propostas realizou-se no período de 16 a 18 de junho de 2003. Com base nos debates e nas respectivas sinalizações, elaborou-se o documento "Proposta de políticas públicas para a educação profissional e tecnológica" (Brasil, 2003b) que, mediante contribuições da sociedade, deu origem ao documento em versão final (Brasil, 2004a).

7 Análises detalhadas sobre as políticas de ensino médio e educação profissional do governo Lula, bem como sobre o percurso contraditório de revogação do decreto $\mathrm{n}^{\circ}$ 2.208/97 podem ser encontradas em Ramos (2005b) e Ramos, Frigotto e Ciavatta (2005).

8 Dentre os representantes do setor público a que nos referimos, estiveram o Conselho de Secretários de Educação (Consed) e o Conselho de Diretores de Centros Federais de Educação Tecnológica (Concefet). No caso do setor privado, estava o Sistema S. Deve-se di-zer que, analisados os documentos dos primeiros, como representantes de redes e sistemas de ensino, frente a outros documentos apresentados separadamente por instituições que compunham tais redes e sistemas, pode-se notar que aqueles advindos dos respectivos conselhos representam posição vencedora, mas não uniforme dentre seus componentes. Isto demonstra que a disputa em torno da revogação do decreto $\mathrm{n}^{\circ} 2.208 / 97$ era mais intensa do que a que se pode captar nas audiências públicas realizadas e nos documentos analisados.

9 Aqui já apresentamos nossa posição quanto à impertinência política e pedagógica desta modalidade existir internamente às instituições, quando o mesmo aluno faz dois cursos distintos. 
10 Giolo (2006) demonstra que em 2004, dos 1804 cursos superiores de tecnologia existentes no país, apenas 359 (19,9\%) estavam em instituições de ensino superior públicas, ficando para o setor privado 1.445 cursos $(80,1 \%)$.

11 Realizamos uma análise sobre essa problemática em Ramos (2006).

12 Referimo-nos particularmente àqueles criados pela lei $\mathrm{n}^{\circ} 6.545 / 78$, quais sejam, os de Minas Gerais, Paraná, e Rio de Janeiro.

13 É com essa terminologia que o documento elaborado pelos Concefet se refere aos Institutos Federais de Educação, Ciência e Tecnologia (Concefet, 2007).

14 Sobre isto, sugerimos a leitura de Frigotto (2006).

15 Usamos estes termos de forma sugestiva ao conceito de transformismo em Gramsci.

\section{Referências}

BERNSTEIN, Besil. A estruturação do discurso pedagógico - classe, código e controle. Petrópolis: Vozes, 1996.

BRASIL. Lei no 6.545, de 30 de junho de 1978. Dispõe sobre a transformação das Escolas Técnicas Federais de Minas Gerais, do Paraná e Celso Suckow da Fonseca em Centros Federais de Educação Tecnológica e dá outras providências. Diário Oficial, Poder Executivo, Brasília, DF, 4 jul. 1978.

Lei no 9.394, de 20 de dezembro de 1996. Estabelece as diretrizes e bases da educação nacional. Diário Oficial, Poder Executivo, Brasília, DF, 23 dez. 1996.

. Decreto no 2.208, de 17 de abril de 1997. Regulamenta o parágrafo 20 do art. 36 e os artigos 39 a 42 da Lei no 9.394, de 20 de dezembro de 1996, que estabelece as diretrizes e bases da educação nacional. Diário Oficial, Poder Executivo, Brasília, DF, 18 abr. 1997.

Ensino médio: construção política. Seminário nacional sobre ensino mé- dio: síntese das salas temáticas. Brasília: MEC/Semtec, abr. 2003a.

Proposta de políticas públicas para a educação profissional e tecnológica. Brasília: MEC/Semtec, dez. 2003b.

Decreto no 5.154, de 23 de julho de 2004. Regulamenta o $\S 2^{\circ}$ do artigo 36 e os arts. 39 a 41 da Lei no 9.394, de 20 de dezembro de 1996, que estabelece as diretrizes e bases da educação nacional, e dá outras providências. Diário Oficial da União, Brasília, DF, 24 jul. 2004a.

Políticas públicas para a educação profissional e tecnológica. Brasília: MEC/Semtec, 2004b.

BRÍGIDO, Raimundo. Certificação de competências profissionais: "discussões". Brasília: OIT/MTE/FAT, 1999.

CASTELLS, Manuel. La era de la información. Economia, Sociedad y Cultura. Fim de milênio, Madri: Alianza Editorial, v. 3, 1998. Coletânea. 
CONCEFET. Manifestação do Concefet sobre os institutos federais de educação, ciência e tecnologia. Brasília, 2007. Mimeografado.

DELUIZ, Neise. Formação do trabalhador: produtividade \& cidadania. Rio de Janeiro: Sahape, 1995.

DUBAR, Claude. A sociologia do trabalho frente à qualificação e à competência. $E d u$ cação \& Sociedade, Campinas, ano 19, n. 64 (especial), p. 87-103, set. 1998.

FRIGOTTO, Gaudêncio. Universidade pública, trabalho e projeto de desenvolvimento no Brasil sob o pêndulo da regressão social. In: MOLL, Jaqueline; SEVEGNANI, Palmira (Orgs.). Universidade e mundo do trabalho. Brasília: Inep, 2006. p. 15-40, 2006.

FRIGOTTO, Gaudêncio; CIAVATTA, Maria. (Orgs.). Ensino médio: ciência, cultura e trabalho. Brasília: MEC, 2004.

GIOLO, Jaime. A educação tecnológica superior no Brasil: os números de sua expansão. In: MOLL, Jaqueline; SEVEGNANI, Palmira (Orgs.). Universidade e mundo do trabalho. Brasília: Inep, 2006. p. 109-134.

MERTENS, Leonard. Sistemas de competencia laboral: surgimiento y modelos. México: Cinterfor/OIT, 1996.

PERRENOU, Philippe. Construir competências desde a escola? Porto Alegre: ArtMed, 1999.
RAMOS, Marise Nogueira. A pedagogia das competências: autonomia ou adaptação?. São Paulo: Cortez, 2001.

O público e o privado na educação profissional: as políticas do MEC. In: PERONI, Vera; ADRIÃO; Teresa. (Orgs.). O público e o privado na educação: interfaces entre Estado e sociedade. São Paulo: Xamã, 2005a. v. 1. p. 31-56.

A gênese do decreto no 5.154/2004: um debate controverso da democracia restrita. In: RAMOS, Marise N.; FRIGOTTO, Gaudêncio; CIAVATTA, Maria. (Orgs.). Ensino médio integrado: concepção e contradições. São Paulo: Cortez, 2005b. v. 1. p. 21-56.

Ciência e tecnologia na institucionalidade Cefet: questões sobre um projeto de educação tecnológica. In: MOLL, Jaqueline; SEVEGNANI, Palmira (Orgs.). Universidade e mundo do trabalho. Brasília: Inep, 2006. p. 135-154.

RAMOS, Marise N.; FRIGOTTO, Gaudêncio; CIAVATTA, Maria. A política de educação profissional no governo Lula: um percurso histórico controvertido. Educação \& Sociedade, São Paulo, v. 26, p. 1087-1113, 2005.

TANGUY, Lucie; ROPÉ, Françoise. Saberes e competências. o uso de tais noções na escola e na empresa. São Paulo: Papirus, 1997. 